\title{
PANGLUKATAN SAPTA GANGGA PERSPEKTIF USADA BALI
}

\author{
Sang Ayu Made Yuliari \\ Fakultas Kesehatan Program Studi Kesehatan Ayurweda \\ Hp. 081337746058/085738537595 \\ Email : yuliari120768@gmail.com
}

\begin{abstract}
ABSTRAK
Bali dengan penduduknya yang dominan Hindu menyebabkan Bali itu unik. Keunikan itu karena budaya yang diilhami oleh ajaran Hindu yang tampak lebih menonjol yaitu upacara upakara yadnya. Salah satu pelaksanaan upacara agama itu adalah manusa yadnya. Panglukatan merupakan bentuk penyucian diri dalam hal ini dilakukan di Pura Tamba Waras dengan Panglukatan Sapta Gangga. Panglukatan Sapta Gangga itu unik karena mendapat panugerahan Dalem Solo dengan tujuh pancoran.Tujuan dari penelitian ini adalah untuk mengetahui panglukatan Sapta Gangga, untuk mengetahui tata caranya dan implikasi setelah melaksanakan panglukatan. Untuk mencapai tujuan itu digunakan teori fenomenologi dan pendekatan Ayurveda serta porposif sampling dengan kualitatif. Adapun hasil yang diperoleh (1) melakukan panglukatan karena mengalami keluhan seperti sakit kepala, nyeri, sakit maag/dyspepsia dan sakit bebai. (2) tata caranya yaitu syarat yang harus dibawa adalah bungkak nyuh gading, bungkak nyuh gadang dan banten pejati. (a) diawali dengan ngaturang bhakti atau berdoa terlebih dahulu, (b) melaksanakan panglukatan ketujuh pancoran yang ada di Pura Tamba waras. (c) panglukatan dengan bungkak nyuh gading oleh Pemangku, dilanjutkan dengan sembahyang di jeroan dan minum air bungkak nyuh gadang yang sebelumnya didoakan terlebih dahulu serta dicampur dengan minyak. (3) Implikasi dari panglukatan tersebut merasa lebih seger, sejuk/tis,tenang, keluhan yang diderita mulai berkurang.
\end{abstract}

Kata Kunci : Panglukatan, Sapta Gangga, Perspektif Usada Bali

\begin{abstract}
Bali with its predominantly Hindu population causes Bali to be unique. The uniqueness is due to the culture which is inspired by Hindu teachings that seem more prominent, namely the ceremony of the ceremony of Yadnya. One of the religious ceremonies is Manusa Yadnya. Panglukatan is a form of self-purification in this case carried out at Tamba Waras Temple with Sapta Gangga Panglukatan. Panglukatan Sapta Gangga is unique because it receives a Dalem Solo award with seven pancoranes. The purpose of this study is to determine the Sapta Gangga Panglukatan, to find out the procedures and implications after implementing Panglukatan. To achieve this goal phenomenological theories and Ayurveda approaches and qualitative sampling are used. As for the results obtained (1) doing fishing because of experiencing complaints such as headaches, pain, heartburn / dyspepsia and bebai pain. (2) the procedure, namely the conditions that must be brought are ivory nyuh, ulemas, gadang, and banter. (a) begins by organizing devotional service or praying first, (b) carrying out the capturing of the seven Pancorans in the Samba Tura Temple. (c) panglukatan with ivory stewed neck by Pemangku, followed by praying in innards and drinking the swollen boil water that was previously prayed for first and mixed with oil. (3) Implications of the Panglukatan feel more fresh, cool / calm, calm, complaints suffered begin to decrease.
\end{abstract}

Keywords: Panglukatan, Sapta Gangga, Perspective of Usada Bali 


\section{PENDAHULUAN}

Masyarakat Bali identik dengan Hindu karena penduduknya lebih banyak menganut agama Hindu. Bali adalah pulau yang sangat kecil dengan beragam budaya sehingga para pelancong luar negeri mengagumi pulau yang kecil ini. Kekaguman itu dirasakan oleh turis karena Bali adalah Unik. Keunikan itu pada tahun 1930 seorang penulis asing bernama Hickman Powel memberi nama pulau ini dengan sebutan The Paradise Island. Nehru menyebutnya dengan The morning of the world. Pulau yang dimaksud oleh kedua penulis tersebut adalah pulau Bali, pulau Dewata tempat bersemayamnya Dewa Dewi dari Kahyangan, tempat para maharsi memantapkan tapa, samadi untuk mencapai kelepasan. Pemberian nama tersebut didasari atas beberapa alasan diantaranya adalah : Pertama mayoritas penduduknya adalah penganut Hindu Dharma yang tercermin dalam berbagai aspek kehidupan masyarakat mulai dari bangun pagi sampai melakukan aktivitas keseharian dan berkesenian seluruhnya mencerminkan nilai-nilai Hindu. Kedua Tata kemasyarakatannya diatur berdasarkan prinsip harmoni Tri Hita Karana, sehingga masyarakatnya dituntut untuk tetap menjaga keselarasan dan keseimbangan dirinya dengan Tuhan sebagai Sang pencipta, antara manusia dengan sesama, dan antara manusia dengan lingkungan alam. Ketiga masyarakat Bali mempunyai aneka ragam kesenian, persembahan dan tontonan yang sarat dengan nilai filsafat kehidupan terutama berhubungan dengan konsepsi dualisme yang dibuat hitam putih, bahwa perilaku yang dilandasi kecurangan, kejahatan, ketidakjujuran, keserakahan pada akhirnya akan mengalami kekalahan dan kehancuran (Triguna, 2011:63-64).

Menjaga kesucian diri di dalam ajaran Yoga Sutra Patanjali disebut dengan sauca. Sauca merupakan salah satu bagian dari panca nyama bratha yang artinya suci bersih lahir bathin. Kebersihan adalah pangkal kesehatan oleh karena itu badan dijaga agar selalu bersih. Dengan bersihnya badan dapat mempengaruhi kesucian jiwa demikian pula kesucian jiwa dapat mempengaruhi kesehatan badan atau jasmani (Wiana, 2006:89). Dalam kitab Manawa Dharma Sastra sloka 109 disebutkan bahwa badan / tubuh dibersihkan dengan air, Atman dibersihkan dengan tapa dan brata. Tapa brata adalah pengendalian gerak indria untuk mencari kenikmatan duniawi. Bila indriya ini tidak dilatih maka atman akan terseret pada kelekatan duniawi. Salah satu untuk menjaga kebersihan dan kesucian badan adalah dengan melukat.

Belakangan ini melukat menjadi kebiasaan bagi umat Hindu di Bali. Di Bali banyak tempat yang dapat dikunjungi untuk melukat seperti Sebatu, Tampak siring, Mangening, Suda mala yang terdapat di Bangli, pancoran Sapta Gangga di Pura Tamba Waras dan banyak lagi tempat lainnya yang mempunyai mata air/ air klebutan. Dari demikian banyak tempat-tempat melukat salah satunya adalah pancoran Sapta Gangga yang terdapat di Pura Tamba Waras.

\section{9}


Panglukatan Sapta Gangga di pura Tamba Waras mempunyai keunikan tersendiri dibandingkan dengan panglukatan di tempat lain.Adapun keunikan itu sesuai dengan nama pura yaitu Tamba Waras, dan pangugerahan Dalem Solo.. Melukat merupakan salah satu bentuk budaya penyembuhan dalam konsep Usada Bali. Dengan adanya peraturan pemerintah nomor 103 tahun 2014 tentang pelayanan kesehatan tradisional. Salah satu bentuk pelayanan tersebut adalah dengan melukat. Dengan adanya peraturan tersebut, pemerintah di Bali yaitu Gubernur ingin membangkitkan kembali cara-cara pengobatan tradisional yang memang sudah ada sejak dahulu. Oleh karena itu perlu kiranya diadakan penelitian lebih mendalam tentang "Panglukatan Sapta Gangga Perspektif Usada Bali".

\section{METODE PENELITIAN}

Penelitian yang berjudul "Panglukatan Sapta Gangga Perspektif Usada Bali” menggunakan pendekatan ayurweda. Ayurveda adalah kitab suci Hindu yang banyak memuat tentang berbagai macam pengetahuan yang erat kaitannya dengan pengobatan. Lontar usada di Bali isinya kebanyakan bersumber pada kitab Ayurveda. Ayurveda banyak mengulas tentang system pengobatan tradisional dan alamiah (naturalis) dimana system pengobatannya tergantung pada penggunaan air, ramuan tumbuh-tumbuhan, mineral dan asam formiat yang berasal dari sarang semut (Nala,1993:27). Panglukatan yang dilaksanakan menggunakan air, air yang berasal dari mata air/air clebutan. Jenis penelitian ini adalah kualitatif, dengan porposif sampling. (Wallace, $1990: 57)$.

\section{PEMBAHASAN}

\subsection{Gambaran Umum Pura Tamba Waras}

Secara geografis Pura Tamba Waras terletak di lereng sebelah selatan Gunung Batukaru, tepatnya di Desa Sangketan, Penebel Tabanan. Pura ini berada satu garis dengan Pura luhur Batukaru, terletak pada ketinggian sekitar 7 meter dari permukaan laut. Pura ini berdiri sekitar abad ke -12. Menurut beberapa catatan sejarah, Raja Tabanan yakni Cokorda Tabanan sakit keras dan tidak ditemukan pengobatannya. Para abdi mencarikan obat sesuai dengan petunjuk gaib yang diterima, dimana akan ada asap sebagai petunjuknya. Setelah berjalan di hutan Batukaru, dijumpai asap mengepul yang berasal dari sebuah kelapa di tanah di dalam rumpun bambu.Setelah memohon di tempat itu didapatkanlah obat. Obat tersebut dihaturkan kepada raja, ternyata sang raja sembuh, akhirnya dibangunlah tempat pemujaan yang diberi nama Tamba waras (www.com https//baliberkarya.com) (akses tanggal 26 Mei 2019). 


\subsubsection{Panglukatan Sapta Gangga.}

Berdasarkan analisis data bahwa panglukatan sapta gangga dilakukan oleh masyarakat khususnya yang beragama Hindu di Pura Tamba Waras karena (1) pada umumnya mempunyai keluhan seperti sakit kepala, susah tidur, maag akut, (2) sakit non medis seperti bebai, (3) ingin menghilangkan cemer / kotor, perasaan yang kurang baik. Hasil ini diperoleh dengan teori fenomenologi yang berasumsi bahwa orang-orang secara aktif menginterpretasi pengalamanpengalamannya dan mencoba memahami dunia dengan pengalaman pribadinya. Fenomenologi juga berusaha mencari pemahaman bagaimana manusia mengkontruksi makna dan konsep penting dalam kerangka intersubyektivitas yaitu pemahaman manusia mengenai dunia dibentuk oleh hubungan manusia dengan alam dan orang lain. Kuswarno Engkus, 2009 (dalam Prastika, 2015 :1). Hal itu dapat dipahami bagi pelaku yang menjalani panglukatan, disamping itu panglukatan merupakan suatu tradisi atau kebudayaan yang telah menginternalisasi secara individu dan membangun kesadaran yang subyektif. Melalui panglukatan masyarakat ingin memperoleh pengalaman dan menjawab keluhan-keluhan yang dialami dan setiap orang mempunyai pengalaman yang berbeda. Panglukatan dilakukan atas dasar keyakinan untuk mendapatkan pengalaman baru seperti sakit bebai yang susah disembuhkan oleh dokter tetapi dapat diatasi dengan pendekatan diri kepada Tuhan melalui panglukatan. Panglukatan Sapta Gangga di Pura Tamba Waras banyak dikunjungi masyarakat karena mampu memberikan vibrasi positif bagi yang melakukan panglukatan.Terkait dengan energy positif Dr. Masaru Emoto mengadakan penelitian tentang air, air yang diberi mantra berubah menjadi kristalkristal air yang membentuk bunga Padma. Demikian juga sebaliknya ketika air diberi makian maka berubah menjadi tidak beraturan /berantakan Dari hasil penelitiannya mengungkapkan bahwa partikel air dapat dipengaruhi oleh suara musik, doa-doa dan kata -kata yang ditulis dan dicelupkan ke dalam air. Partikel air yang dikumpulkan tenyata dapat berubah-ubah sesuai dengan perasaan manusia di sekelilingnya, yang secara tidak langsung mengisyaratkan pengaruh perasaan terhadap klasterisasi molekul air yang terbentuk oleh adanya ikatan hidrogen (www.com,14 Agustus 2019). Hal ini sesuai dengan hasil penelitian di lapangan bahwa melukat dapat mengatasi keluhan -keluhan yang dialami oleh masyarakat karena tempat melukat merupakan tempat suci dan diiringi dengan puja mantra sehingga memberi pengaruh yang baik bagi kesehatan.

Panglukatan berhubungan dengan air. Air dalam agama Hindu sangat disakralkan karena setiap pelaksanaan upacara air selalu hadir di dalamnya. Dalam pandangan agama Hindu di Bali, begitu pula tradisi-tradisi agraris local Bali, air mendapat perlakuan secara khusus, sehingga Hooykaas menyebut agama orang Bali sebagai agama tirtha dalam karyanya yang berjudul Agama Tirtha : Five Studies In Hindu-Balinese Religion (1964). Studi Hooykaas 
memang benar adanya karena orang Bali memperlakukan air dengan sacred. Sumber-sumber air seperti celebutan dirawat dan disakralisasi dengan mendirikan palinggih,, bebaturan, candi, tempat orang Bali mengucapkan syukur atas berkah yang diberikan (dalam Gelgel,2015:vi). Air yang diberi mantra disebut dengan tirtha sehinga menjadi suci. Air adalah kebutuhan hidup, menurut Thales air adalah hakikat segala sesuatu Hadiwijono, 2002 (dalam Sukarma, 2015:93).Selanjutnya dalam Bhagawadgita ,VII.4 dijelaskan sebagai berikut.

Bhumir apo nalo vayuh

Kam mano buddhir eva ca

Ahamkara iti yam me

Bhinna prakrtir astadha.

Artinya bumi, air api, angin, akasa, pikiran dan budi, perasaan keakuan ini adalah delapan bahagian dari alam-Ku. Untaian sloka di atas memberikan pesan tentang hakikat material itu terdiri atas delapan antara lain :air, api, udara, tanah, ether, pikiran ,budhi dan ego. Dari delapan material itu salah satunya ada unsur air. Air sangat penting bagi kehidupan manusia dan makhluk hidup lainnya terlebih bagi umat Hindu di Bali. Air bagi agama Hindu banyak digunakan dalam pelaksanaan upacara yadnya. Manusia tidak mapu membuat air/menciptakan air demikian juga sebaliknya manusia dan semua manifestasi berasal darinya, hal inilah yang menyebabkan air begitu penting dalam kehidupan. Air yang sangat penting ini dan diyakini oleh umat Hindu karena air mempunyai kekuatan yang diungkapkan oleh Sukarma ( 2015 :94 ) dalam "Revitalisasi Agama Tirtha Di Bali “ (2010 :21) dalam "Pudarnya Pesona Agama Tirtha seperti berikut.

Orang Bali meyakini bahwa air mewarisi sifat-sifat Wisnu, dewa penyelenggara kehidupan. Dengan Pengada dan tujuan kehidupan, air kehidupan orang Bali mengalir sepanjang tradisi desa pakraman. Tri Murti ini diyakini sebagai manifestasi Bhatara Siwa dan persembahan kepadaNya tidak sempurna bila tidak ada air. Dalam kesatuannya dengan tridatu,air diyakini memiliki kekuatan gaib-mistis dalam rangka memperluas dunia manusia ke dunia dewa-dewi. Begitulah orang Bali menerima dan mengapresiasi air untuk memelihara dunia-kehidupan (bhuwana Agung dan bhuwana alit). Dunia yang diproyeksikan pada kehidupan di sini (bukan akhirat, surga, neraka-moksa).Sejalan dengan hal tersebut umat Hindu di India juga memandang air sangat penting untuk semua ritual dalam agama Hindu seperti air digunakan untuk poojaas (ritual) dan untuk abhihsekas atau mandi dari Dewa dan air yang dikumpulkan setelah mandi dari Dewa dianggap sangat sakral.

Panglukatan di tempat - tempat patirtan seperti tirtha Empul, Sebatu, Tirtha Sudamala, Pura Selukat, pada umumnya sama, akan tetapi panglukatan di Pura Tamba Waras dengan pancoran Sapta Gangga.Panglukatan diyakini oleh masyarakat karena memberikan manfaat dan vibrasi yang positif serta mampu mengatasi keluhan-keluhan bagi yang melakukannya. Hal ini dapat diperoleh karena (1) tempat pemujaan disakralkan, (2) air diberi puja mantra oleh sulinggih sehingga menjadi berkhasiat.Terkait dengan nama Sapta Gangga tersebut ada mantra untuk 
membuat tirtha yang dilantunkan oleh sulinggih atau pandita dengan tujuh sungai suci yang terdapat di India antara lain sebagai berikut.

Mantram Apsu Dewa

Om Apsudewa pawitrani

Gangga dewi namostute

sarwa klesa winasa ya

toyane parisuddha te

sarwa rogha winasa ya,sarwabhogam ewapnuyat

sarwa papa pataka winasa ya,sarwa rogha dosa winasa ya

Mantram Gangga Dewi Stawa

Om Gangga Sindhu Saraswati,

Suyamuna godhawari,Kaweri sarayu

Mahendra Tanaya carma wati wenukam. (Wijayananda,2003:19-20).

Berdasarkan mantram tersebut diketahui bahwa panglukatan di tempat suci seperti beji dapat memberikan kesembuhan menghilangkan penderitaan, penyakit dan segala penderitaan dapat dimusnahkan. Dengan keyakinan dan pikiran yang kuat serta sugesti dari mantram tersebut sehingga masyarakat berduyun-duyun untuk melakukan panglukatan. Seperti diketahui adanya penyakit berasal dari pikiran. Di dalam kitab Yoga Sutra Bab II.3 disebutkan sebagai berikut.

Avidyaasmitaragadvesaabhinivesah klesah (avidya, asmita, raga, dvesa, abhinivesa). Kelima klesa inilah yang menyebabkan kesengsaraan dan ditambah lagi pikiran yang berfluktuasi (ksipta, mudha, viksipta, ekagra,nirodha). Panglukatan juga merupakan suatu pembelajaran untuk meningkatkan kualitas diri karena akan timbul kesadaran akibat vibrasi positif.

Menurut Usada Bali air digolongkan ke dalam golongan sarana. Air ini berfungsi sebagai alat angkut obat yang hidup sampai ke tempat penyakit. Air hidup ini disebut dengan Amertha. Melukat merupakan suatu upacara penyucian di Bali yang dilakukan untuk menghilangkan penyakit atau kecemeran yang diderita(leteh) oleh seseorang. Orang dimandikan dengan air yang telah diberi mantra dan doa-doa oleh Balian atau Pendeta. Air suci ini akan melebur (angleburaken) sarwa mala (Nala,1993:211). Ketika seseorang mengalami keluhan atau jatuh sakit, maka dilakukan perlakuan atau manipulasi untuk mengatasi penyakitnya dengan melukat dan perlakuan lain seperti pijat, urut, mandi uap, boreh/lulur. Panglukatan merupakan salah satu bentuk tindakan dalam pengobatan tradisional/usada Bali dengan mandi atau menyiramkan air ke seluruh tubuh melalui tujuh pancoran yang terdapat di Pura Tamba waras.Hal ini juga didukung oleh Arwati (2005:1) bahwa melukat merupakan bagian dari pelaksanaan upacara manusa yadnya. Melukat bertujuan untuk membersihkan dan menyucikan diri pribadi secara lahir dan bathin yang diakibatkan oleh malapetaka, diperoleh dari dosa-dosa baik itu dari sisa dosa terdahulu maupun perbuatan di masa hidupnya.

\subsubsection{Tata Cara Panglukatan Sapta Gangga}


Panglukatan dengan sarana utamanya adalah air diyakini mempunyai kekuatan atau energy yang bersifat alamiah dan dapat bermanfaat memberikan kesembuhan bagi yang melakukannya. Melakukan panglukatan ini diperlukan suatu proses, tata cara dan tuntunan yang benar dari seorang sulinggih, pemangku pura setempat, balian atau guru spiritual. Untuk mendapatkan hasil yan maksimal ada sarana lain yang digunakan baik sebelum melukat maupun pelaksanaan melukat. Berdasarkan analisis data Pemangku pura setempat, sulinggih menyatakan tata cara panglukatan dilakukan sesuai dengan ketentuan petunjuk pemangku pura setempat atau yang memimpin upacara panglukatan. Melakukan panglukatan di Pura Tamba Waras menurut pemangku pura ada beberapa langkah yang dapat digolongkan sebagai berikut.

Menyiapkan sarana bungkak nyuh gading dan bungkak nyuh gadang serta banten Pejati dan panglukatan.Sebelum melakukan panglukatan diawali dengan (1) menyiapkan sarana bungkak nyuh gading dan nyuh gadang, (2) Banten Pejati, (3) Pelaksanaan panglukatan diawali dengan ngaturang bhakti sembahyang atau berdoa terlebih dahulu, (4) melaksanakan panglukatan ketujuh pancoran yang ada di Pura Tamba waras atas petunjuk pemangku. Ketujuh pancoran itu antara lain (a) Tirtha Sanjiwani, (b) Tirtha Kamandalu,(c) Tirtha Kundalini, (d) Tirtha pawitra, (e) Tirtha Maha pawitra, (f) Tirtha Pangurip dan (g) Tirta Pasupati.(5) Setelah melakukan panglukatan ke tujuh pancoran tersebut dilakukan (6) panglukatan dengan bungkak nyuh gading oleh Pemangku. Menurut Mangku Dalem Solo bila penyakitnya sudah kronis/ non medis dilanjutkan dengan sembahyang di jeroan dan minum air bungkak nyuh gadang yang sebelumnya didoakan /diberi puja mantra terlebih dahulu oleh pemangku serta dicampur dengan minyak kelapa.

Berdasarkan pendekatan Ayurveda salah satu bentuk pengobatan adalah dengan air yaitu melalui panglukatan. Air dapat merespon apapun yang disampaikan oleh manusia karena air itu hidup. Emoto dalam penelitiannya tentang air menemukan bahwa setelah air diberi mantra, partikel air berubah membentuk Kristal yang sangat indah demikian sebaliknya. Pengobatan Usada atau tradisional di Bali kebanyakan bersumber pada Ayurveda. Ayurveda terdapat pada kitab suci Hindu yaitu Veda. Ayurveda banyak membahas tentang system pengobatan tradisional dan alamiah (naturalis) dengan bergantung pada air sebagai salah satu sarana yang digunakan. Usada merupakan turunan dari Ayurveda, dimana Ayurveda merupakan bagian dari kitab suci Veda.

Di dalam pelaksanaannya merujuk pada kitab Atharva Veda. Atharva Veda merupakan bagian dari Catur veda yang banyak membahas tentang penyakit dan pengobatannya. Inti ajaran Atharva veda dalam mengobati berbagai macam penyakit menggunakan empat pendekatan yaitu : (1) pendekatan mistik yaitu dengan menggunakan sajen agar mendapat kekuatan dan anugerah untuk melawan penyakit, (2) pendekatan psikologi yaitu melakukan 
persembahyangan, samadi, brata , tapa agar memperoleh ketenangan batin atau juga dengan mekidung menyanyikan nynyian suci, (3) hubungan pasien dengan pengobat yaitu meyakinkan pasien bahwa penyakitnya dapat disembuhkan, (4) mempergunakan bermacam-macm ramuan obat dalam berbagai bentuk serta tindakan manipulasi untuk mengobati penyakit yang diderita (Nala,2001:16-17).

Melaksanakan panglukatan ketujuh pancoran yang ada di pura Tamba Waras atau pancoran Sapta Gangga merupakan salah satu bentuk pengobatan dalam usada maupun Ayurveda. Panglukatan juga diiringi dengan doa, mantra-mantra dan tujuan untuk kesehatan, kemakmuran, kehidupan, kesidian. Menurut pemangku setempat menyatakan ketujuh pancoran tersebut merupakan panugerahan sehingga diberi nama pancoran Sapta Gangga. Pancoran pertama yaitu pancoran Sanjiwani. Sanjiwani adalah kekuatan kesucian sekala dan niskala dalam mengatur sifat moha dan loba yang perlu dikendalikan serta dinetralisir dalam kehidupan. (1)Tirtha Sanjiwani sebagai anugerah dari Widyadari Gagar Mayang sebagai prabawaNya dalam kekuatan Sang Hyang Iswara yang berfungsi sebagai pelebur atau pralina kehidupan.(www.com, akses tanggal 28 -8-2019). Tirtha sanjiwani juga disebut sebagai air suci untuk dapat hidup abadi (Anonim,2005:129). (2) Tirtha Kamandalu adalah tirtha untuk menumbuhkan perasaan dan pikiran suci dari kekotoran fisik, spiritual sehingga merupakan simbolis pembersihan tri premana (sabda, bayu, idep), (3) Tirtha Kundalini yaitu kekuatan Illahi yang sedang tidur dalam suatu makhluk yaitu manusia,(Anonim,tt:25), (4)Tirtha pawitra dan(5) tirtha maha pawitra yaitu air suci untuk membersihkan klesa/penyakit (Anonim,2005"129), (6) Tirtha pangurip yaitu tirtha untuk membangkitkan diri atau untuk mendapatkan kesembuhan/waras dalam kata urip waras dirghayusa sang inambeyan ( Wijayananda,tt:24), dan (7) Tirtha Pasupati yaitu air pemberkatan dalam hal ini adalah Siwa sebagai dewa utama untuk memberikan anugerah pemberkatan agar mendapatkan kesidian, kejayaan dan kekuatan. Pasupati dalam Kamus Agama Hindu diartikan Siwa, upacara pemberkatan(Anonim,tt:89).

Berdasarkan uraian di atas panglukatan dengan tujuh pancoran yang ada di Pura Tamba Waras dapat dipahami bahwa dalam menjalani hidup tidak lepas dari karunia Ida Sanghyang Widhi dan alam semesta sebagai sumber kehidupan. Bhuwana agung dan bhuwana alit selalu berhubungan sehingga perlu badan atau tubuh ini dibersihkan baik secara sekala maupun secara niskala dengan berbagai macam upacara atau panglukatan. Dengan panglukatan ketujuh pancoran tersebut diharapkan dapat membangkitkan kesadaran diri dan kesucian diri sehingga dapat terhindar dari sakit, penderitaan dengan pengendalian diri. Hal ini sesuai dengan ajaran Yoga Patanjali yaitu Sauca yang merupakan bagian dari panca nyama bratha. Sauca artinya suci lahir dan batin melalui kebersihan badan dan kesucian batin. Oleh karena kebersihan 
adalah pangkal kesehatan. Kebersihan badan akan memberi pengaruh terhadap rohani /jiwa. Jiwa /atman dibersihkan dengan brata da tapa. Tubuh pikiran, indria dan budhi adalah pakaian sang Atman oleh karena itu harus selalu dijaga kesuciannya (Wiana,2006:90). Panglukatan dengan panugerahan oleh Siwa dalam hal ini sebagai dewa pasupati segala usaha untuk kesembuhan akan dapat dicapai. Hal ini sesuai dengan fenomena masyarakat melakukan panglukatan untuk mendapatkan pengalaman secara spiritual.

Disamping itu pula panglukatan dilakukan dengan bungkak nyuh gading (kelapa) oleh pemangku baik disiramkan ke seluruh tubuh maupun diminum. Kelapa dalam Ayurveda disebut dengan Narikela. Buah narikela/kelapa mempunyai sita guna (dingin), sulit dicerna. Air buah kelapa sangat baik dipergunakan untuk membersihkan kandungan kencing (bhasti) tetapi dapat menyebabkan gas dalam lambung. Daging buahnya dapat dikonsumsi sebagai bahan makanan, untuk meningkatkan bala atau kekuatan, tetapi menurunkan unsur tri dosha vatta, pitta dan rakta (darah). Air buahnya sering dipergunakan sebagai obat bagi mereka yang menderita daha, rasa panas terbakar. Air buah kelapa pada umumnya sebagai tindika, pencahar, dapat dipergunakan sebagai obat trsna (penyakit kehausan dan menurunkan unsur pitta (Nala,2001:176). Selanjutnya Sudaryati menyebutkan air kelapa mengandung banyak gizi dan terkenal sebagai minuman untuk memulihkan tingkat elektrolit dalam tubuh dan juga banyak manfaat lainnya. Nutrisi yang terkandung dalam air kelapa antara lain: kalium,magnesium dan vitamin c. Adapun manfaat yang lainnya yaitu air kelapa dapat membantu menghilangkan kelebihan minyak pada kulit juga dapat mengontrol minyak pada kulit dan memberikan sinar alami pada wajah. Caranya : mencuci wajah dengan air kelapa secara terus-menerus kontinyu setiap hari (2015:30). Selain kelapa juga menggunakan banten pejati. Banten adalah sesaji (Anonim,2005:19). Pejati yang berarti suatu kebenaran merupakan hasil dari sebuah pemahaman yang lahir dari makna sebuah bahasa terbangun dan terstruktur dengan baik. Banten/upakara merupakan hasil kreativitas manusia disinilah keterkaitan manusia dengan alam dan sesamanya sehingga dapat dijadikan sarana dalam bentuk panglukatan (Prastika, 2015:14).

\subsubsection{Implikasi Panglukatan Sapta Gangga}

Berdasarkan analisis data implikasi panglukatan Sapta Gangga antara lain: badan terasa lebih seger, tenang, keluhan mulai berkurang, tidur nyenyak, makan jadi lebih enak. Hal ini sesuai dengan pengertian sehat menurut Ayurveda disebut svastha/svasthya. Dalam kitab Susrutha Samhita 15/41 A disebutkan sebagai berikut. Shamadosha shamagnischa shamadhatu malakriya, prashannatmendriya manah svastha ityabhidhiyate. Maksud dari sloka tersebut adalah bila seseorang yag memiliki keseimbangan dalam dosha dan agni (enzim pencernaan 
dan metabolism ) dhatu (jaringan tubuh ) berfungsi dengan baik, serta mala (limbah, ekskreta) dibuang secara teratur mempunyai kebahagiaan atma(spirit), indriya, manah.

Berdasarkan uraian tersebut di atas jelas bahwa manusia yang sehat itu tidak lepas dari unsur fisik, indriya, mental, pikiran, jiwa/atman. Jadi sehat tidak hanya menyangkut fisik, mental saja akan tetapi spiritualnya juga sangat penting karena disitu ada unsur kepercayaan dan keyakinan kepada Tuhan Yang Maha Esa bahwa segala makhluk hidup berasal dariNya. Hal ini juga sejalan dengan ajaran agama Hindu, tujuan utama manusia hidup adalah moksartham jagadhita ya ca iti dharma (Nala,2001:69). Untuk mencapai tujuan tersebut manusia harus dilengkapi dengan catur purushartha sebagai bekal untuk meraih tujuan individual. Yang dimaksud catur purushartha menurut Ayurveda adalah (1) Dharma yaitu menekuni ajaran agama sehingga mempunyai kebajukan, kebenaran, keteguhan hati, kepercayaan diri, (2) Artha yaitu mengumpulkan materi agar hidup sejahtera,(3) Kama yaitu menikmati keinginan dalam batas kewajaran misalnya berolahraga, berdarmawisata untuk menjaga agar badan tetap sehat, (4) Moksa yaitu berusaha agar hidup tetap bahagia, aman dan damai. Moksa tidak semata-mata dapat diraih setelah meninggal, tetapi moksa juga didapat dalam kehidupan ini. Dengan hidup bahagia dan sejahtera maka tubuh akan sehat sehingga dapat berkarma secara optimal (Wiana,2006 :69). Dari tujuan yang mulia itu terselip pesan bagaimana manusia harus berusaha keras dalam hidup untuk menjaga keseimbangan antara tugas dan kewajiban dengan selalu mengingat kebenaran sebagai landasan. Segala sesuatu yang diarih dengan cara yang benar akan menghasilkan kebahagiaan dan inilah tujuan hidup yang utama.

Hidup sehat merupakan dambaan bagi semua orang, hal ini dapat dicapai dengan melaksanakan panglukatan yang berimplikasi pada ketenangan. Dengan pikiran yang tenang akan lebih mudah dapat menerima segala sesuatu baik itu hal yang sedih, gembira, susah dan senang. Melalui panglukatan memperoleh kesejukan/tis yang berimplikasi pada tubuh sehingga menimbulkan rasa bahagia. Ketika perasaan bahagia, susah, senang itu dapat dikelola dengan baik maka tubuh akan sehat. Munculnya suatu penyakit tidak semata-mata dari fisik tetapi lebih banyak disebabkan oleh pikiran. Karena itu untuk membantu agar dapat mengendalikan pikiran dilakukan dengan panglukatan. Mengendalikan pikiran sangat susah karena itu perlu dilatih baik melalui sembahyang maupun dengan dhyana/meditasi. Ada lima tingkah polah pikiran atau disebut dengan fluktuasi pikiran antara lain: (1) Ksipta yaitu pikiran tidak pernah diam ibarat kera/monyet yang selalu melompat ke sana ke mari, (2) Mudha artinya lamban dan malas yang disebabkan pengaruh tamas yang menguasai pikiran, (3)Viksipta artinya bingung, kacau karena dipengaruhi oleh rajas. Karena pengaruh rajas pikiran mampu mewujudkan pada kebajikan, pengetahuan dan tahap ini merupakan tahap pemusatan pikiran, (4) Ekagra artinya 
pikiran mulai terpusat karena dipengaruhi oleh sattva sebagai persiapan untuk menghentikan perubahan-perubahan pikiran, (5) Niruddha yaitu terhentinya semua kegiatan pikiran sehingga muncullah ketenangan. Ekagra dan niruddha merupakan persiapan utnuk mencapai tujuan akhir yaitu kelepasan (Sura,dan Yasa,2011:24). Demikian pengendalian pikiran sangat sulit oleh karena itu menurut ajaran Hindu di Bali dibantu dengan berbagai macam upacara yadnya. Tujuannya adalah untuk melatih pikiran mengarah kepengendalian diri lebih dalam sehingga timbul kesadaran sejati. Lebih lanjut dijelaskan dalam kitab Sarasamuscaya sloka 80 tentang pikiran sebagai berikut.

Apan ikang manah ngaranya, ya ika itning indriya

Maprawrtti ta ya ring cuhacubhakarma

Matangnyan ikang manah juga prihen kahrtanya sakareng.

Artinya.

Sebab pikiran itu namanya adalah sumbernya indriya, ialah yang menggerakkan perbuatan baik buruk itu, karena itu pikiranlah yang patut diusahakan pengendaliannya (Pudja,1980:48). Melalui panglukatan diharapkan dapat menguasai indriya yang bersumber dari pikiran sehingga ketenangan itu dapat dicapai. Dengan pikiran yang tenang maka horman endorphin akan meningkat yang diproduksi oleh tubuh. Hormon endorphin menimbulkan rasa senang dan bahagia hal inilah yang dapat mengatasi penyakit seseorang.

\section{PENUTUP}

Berdasarkan uraian di atas dapat disimpulkan sebagia berikut.

1. Panglukatan Sapta Gangga dilakukan karena banyak mengalami keluhan seperti sakit kepala, nyeri, maag/dyspepsia, sakit bebai/non medis.

2. Tata caranya dengan membawa bungkak nyuh gading dan bungkak nyuh gadang, banten pejati. (1) Diawali dengan sembahyang, (2) melakukan panglukatan atas petunjuk pemangku, ke tujuh pancoran Sapta Gangga (3) sembahyang di jeroan dan minum air bungkak nyuh gadang yang telah diisi minyak oleh pemangku.

3. Implikasi dari panglukatan tersebut yaitu keluhan sudah mulai berkurang, sejuk/tis, rasa tenang dan bahagia sehingga hormone endorphin meningkat.

\section{DAFTAR PUSTAKA}

Ananda Kusuma Sri Reshi,1986. Kamus Bahasa Bali.CV.Kayumas. 
Anonim, 2005. Kamus Istilah Agama Hindu.Program Pengembangan Lembaga - Lembaga Sosial Keagamaan Dan Lembaga Pendidikan Agama.

Anonim, 2005. Kamus Bali Indonesia.Balai Bahasa Denpasar. Pusat Bahasa Departemen Pendidikan Nasional.Cetakan Pertama.

Anonim, 2010. Canang Sari Dharmasmrti Mengenang Bhakti Prof.Nala.Penerbit Widya Dahrma Denpasar.Dicetak oleh percetakan Mabhakti. ISBN: 978-602-96754-5-0

Arifah,Nur. 2016. Panduan Mudah menyusun Skripsi, Tesis, dan Disertasi. Yogyakarta. Araska.

Arwati.2005. Upacara Melukat Untuk Ibu-Ibu Umat se-Dharma Hindu.

Bagus Loren,2005. Kamus Filsafat.Penerbit PT Gramedia Pusaka Utama Jakarta. Cetakan keempat.

Koentjaraningrat,1984. Kebudayaan Mentalitas dan Pembangunan. Jakarta. Gramedia.

Nala Ngurah.2001. Ayurveda Ilmu kedokteran Hindu I. Penerbit Upada Sastra Denpasar.

---------,1993.Usada Bali.Penerbit PT Upada Sastra Denpasar

Prastika,2015.Melukat Spa Tradisional Bali. Jurnal Kesehatan Hindu Ayurweda. Vol.2. ISSN 2407-6481.

Peter Salim, Yenny Salim. 2002. Kamus Bahasa Indonesia Kontemporer, Edisi Ke Tiga

Pudja, Gede,1980. Sarasamuscaya.Cetakan II. Jakarta.

Sukarma,2015 Revitalisasi Agama Tirta Di Bali. ISBN 978-602-7610-38-5 Penerbit Pustaka Ekspresi.

Sura, I Gede dan Suka Yasa,2011. Samkhya dan Yoga . ISBN 978-979-19870-0-4. Penerbit Widya Dharma.

Triguna, 2011. Mengapa Bali Unik?. Penerbit Pustaka Jurnal Keluarga.Jakarta. Cetakan Pertama.

Wallace, 1990. Metode logika Ilmu Sosial. Jakarta. Bumi Aksara.

Wiana,2007.Tri Hita Karana Menurut Konsep Hindu.Paramitha Surabaya.

----------,2006. Beragama Bukan Hanya Di Pura. Penerbit Yayasan Dharma Naradha.

Wijayananda, Ida Pandita Mpu Jaya,2003. Agem-Ageman kepemangkuan. Penerbit Paramita Surabaya.

Wojowarsito, tt.Kamus Kawi Indonesia.Penerbit. C.V. Pengarang.

www.com baliberkarya.com, 26 Mei 2019 


\section{LAMPIRAN}

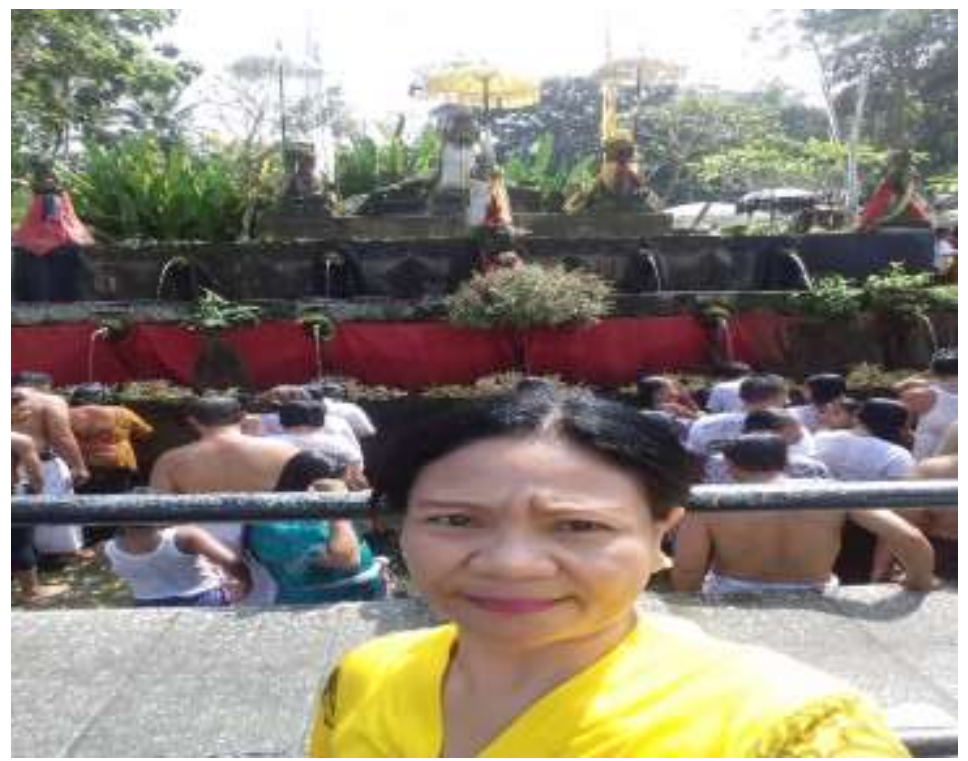

Masyarakat yang sedang melaksanakan panglukatan (sumber penelitian)

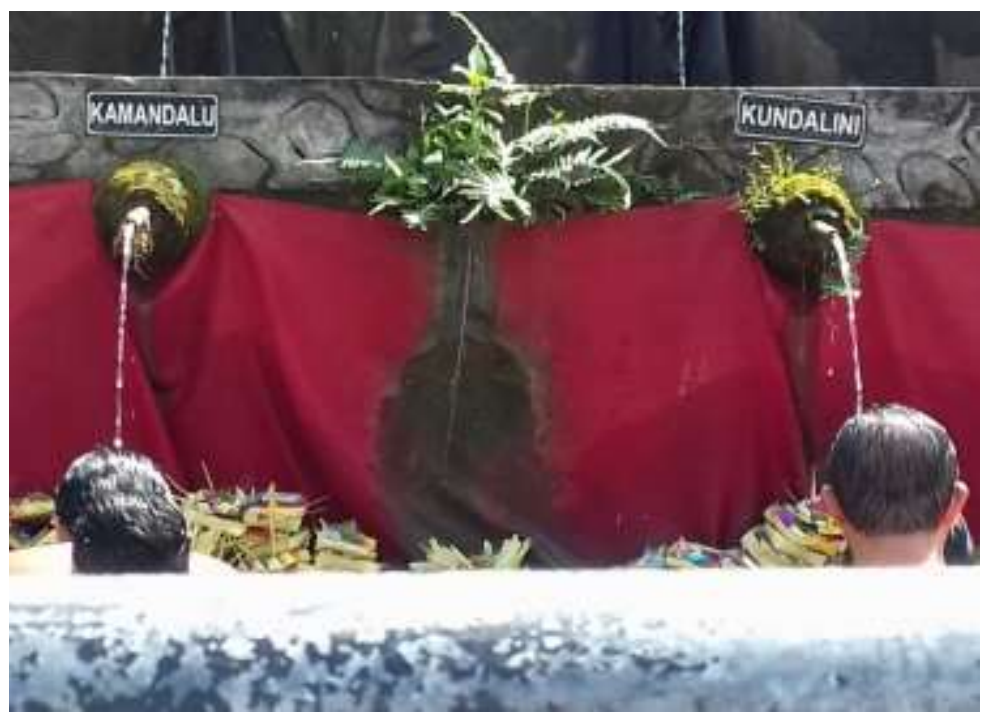

Nama pancoran di tempat panglukatan (sumber penelitian) 


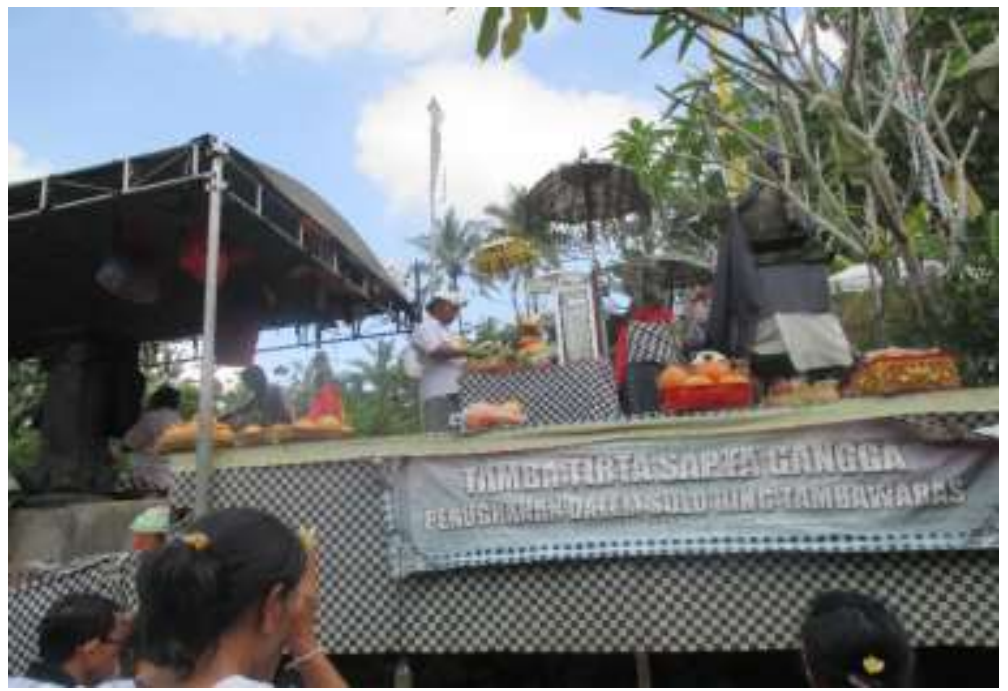

Asagan tempat Sembahyang sebelum panglukatan

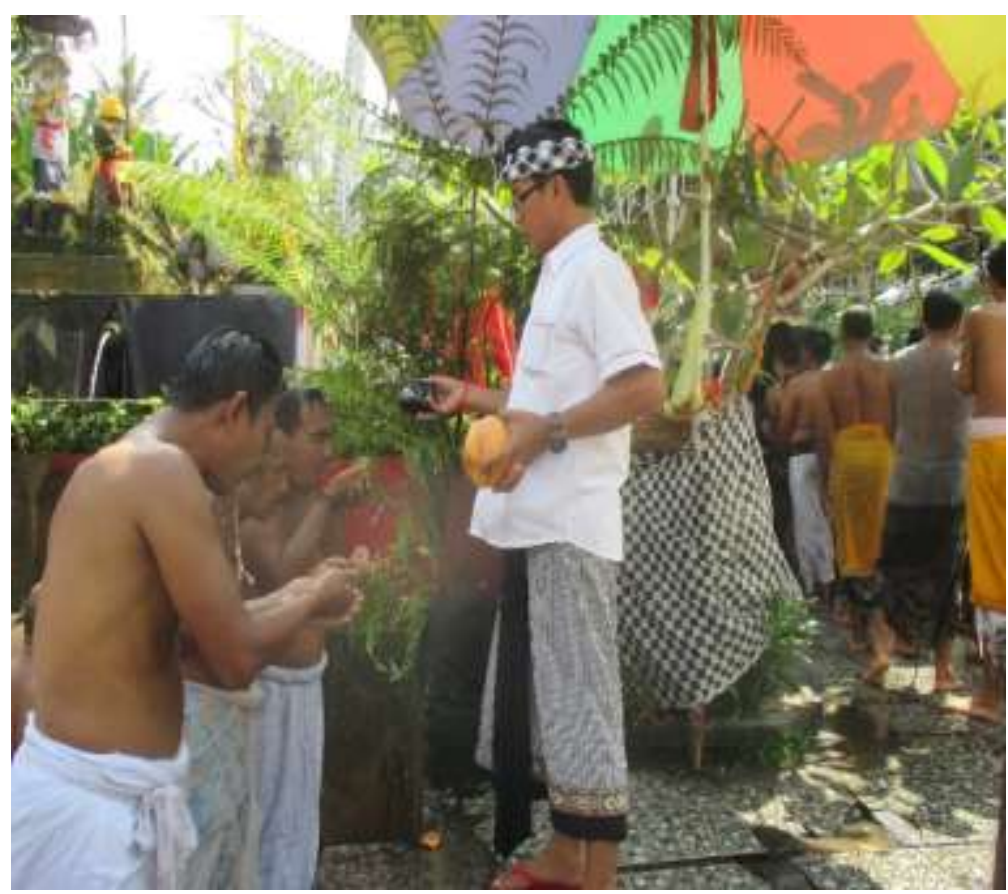

Panglukatan dengan bungkak nyuh gading 